\title{
Endovascular Treatment of Abdominal Aortic Aneurysms with Complex Anatomy: Preliminary Results of a Second-Generation Stent Graft with a Dual-Ring Design
}

\author{
Patrick Bastos Metzger ${ }^{1}$, Eduardo Rafael Novero' ${ }^{1}$ Fabio Henrique Rossi ${ }^{1}$, Samuel Martins Moreira ${ }^{1}$, \\ Heraldo Antônio Barbato' ${ }^{1}$ Nilo Mitsuru Izukawa' ${ }^{1}$, Vanessa Luciene Abreu de Marco², \\ Manoel Nicolas Cano ${ }^{1}$, Antonio Massamitsu Kambara ${ }^{1}$
}

\begin{abstract}
Background: Endovascular treatment has revolutionized the therapeutic approach to abdominal aortic aneurysms due to its low morbidity and mortality rates. Despite technological advances, there are still anatomical limitations to the use of stent grafts. This study aimed to evaluate the immediate clinical results in patients with complex abdominal aortic aneurysms treated with a second-generation stent graft. Methods: This was an observational, prospective, non-randomized, single-centre study with a series of patients who underwent endovascular repair of complex infra-renal abdominal aortic aneurysms using a stent graft with a dual-ring stent design (Anaconda' ${ }^{\mathrm{TM}}$, Vascutek - Terumo, Inchinnan, Scotland). Clinical and angiographic characteristics, technical and therapeutic success rates, morbidity and mortality, and perioperative reintervention rates were evaluated. Results: Between February 2010 and December 2011, 108 consecutive patients with aortic aneurysms were treated; 16 had complex abdominal aortic aneurysms treated with the Anaconda ${ }^{\mathrm{TM}}$ AAA Stent Graft System. The mean age was $76 \pm 7$ years and $75 \%$ were males. Technical success was observed in $94 \%$ of the cases and therapeutic success was achieved in $75 \%$ of the cases. There was one postoperative death. The most prevalent perioperative complications were surgical wound bleeding (2/16) and peripheral embolism (2/16). Reinterventions were required in $12.5 \%$ of the patients during follow-up. Conclusions: In this study, the second-generation Anaconda ${ }^{\mathrm{TM}}$ Stent Graft System was effective and provided satisfactory immediate results in the treatment of complex infra-renal abdominal aortic aneurysms.
\end{abstract}

DESCRIPTORS: Aortic aneurysm, abdominal. Blood vessel prosthesis. Arteriosclerosis. Atherosclerosis.
RESUMO

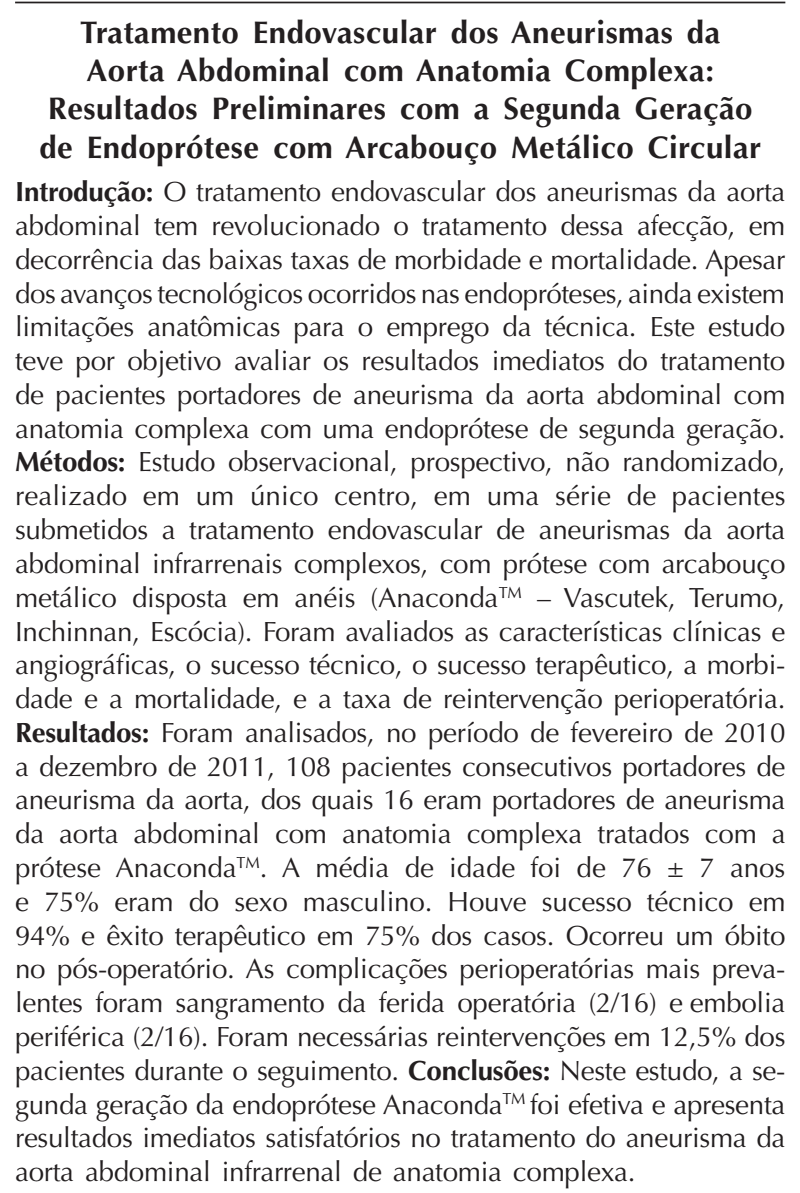

DESCRITORES: Aneurisma da aorta abdominal. Prótese vascular. Arteriosclerose. Aterosclerose.

\footnotetext{
Instituto Dante Pazzanese de Cardiologia - São Paulo, SP, Brazil

2 Faculdade de Medicina da Universidade de São Paulo (FMUSP) São Paulo, SP, Brazil. 
$\mathrm{F}$ or many years, surgical treatment has been the standard therapy for patients with abdominal aortic aneurysm. ${ }^{1}$ Since the introduction of the endovascular repair technique by Parodi et al. ${ }^{2}$ in 1991, which aimed to decrease intra- and postoperative morbidity and mortality, the materials used for this treatment have been constantly improved. These improvements have led to better medium and long-term results. ${ }^{3}$

Endovascular repair is preferably indicated for high-risk surgical patients due to clinical comorbidities or for those patients with anatomic difficulties for an open surgical approach (hostile abdomen). Despite aggressive technological development, the ideal endograft has not yet been designed, and there are still technical limitations regarding the percutaneous procedure due to local anatomic variation, which hinders the adequate exclusion of the aneurysm.

Three major studies (Comparison of EndoVascular Aneurysm Repair open repair in patients with abdominal aortic aneurysm - EVAR 1, Endovascular Aneurysm Repair and outcome in patients unfit for open repair of abdominal aortic aneurysm - EVAR 2, and Dutch Randomized Endovascular Aneurysm Management - DREAM) ${ }^{4-6}$ have shown that perioperative morbidity and mortality rates (within 30 days after the procedure) were favourable for endovascular treatment; however, when mortality rates were compared with that of the surgical technique, they were similar after one year of aneurysm treatment. The reintervention rates were greater in the endovascular treatment group and varied from $14 \%$ to $26 \%$. This fact motivated the development of more versatile and flexible endografts, which would better adapt to existing anatomic obstacles in the aneurysm neck and aortoiliac bifurcation, as well as promote better sealing of its connections. A better seal would help prevent undesired endoleaks and decrease reintervention rates.

The aim of this study was to conduct an analysis of the perioperative results achieved through the use of a second-generation stent graft with a dual-ring stent design (Anaconda ${ }^{\mathrm{TM}}$, Vascutek - Terumo, Inchinnan, Scotland) in the treatment of complex infra-renal abdominal aortic aneurysms.

\section{METHODS}

This was an observational, prospective, non-randomized study conducted at a cardiovascular disease centre in the state of São Paulo between February of 2010 and December of 2011. During the study period, 108 consecutive patients with aortic aneurysms were percutaneously treated with the Anaconda ${ }^{\mathrm{TM}}$ second-generation stent graft; 16 patients had complex infra-renal abdominal aortic aneurysms.

\section{Inclusion and exclusion criteria}

Patients with abdominal aortic aneurysm and indication for elective repair using the diameter criterion
(> $55 \mathrm{~mm}$ in men and $>50 \mathrm{~mm}$ in women) or due to the presence of symptoms were included in the study. The anatomical criteria for using the stent graft were the presence of angulation in the proximal aortic neck (defined as the angle between the greater axis of the aneurysm neck and the greater axis of the aneurysm) and/or aortoiliac bifurcation of $>60$ degrees. The study excluded patients presenting with a proximal neck $<15 \mathrm{~mm}$, thrombus, calcification $>50 \%$ of the neck circumference, diameter of external iliac arteries $<7 \mathrm{~mm}$, serum creatinine $>2 \mathrm{mg} / \mathrm{dL}$, or creatinine clearance $<30 \mathrm{~mL} / \mathrm{min}$.

\section{Techniques used}

The diagnosis and treatment of abdominal aortic aneurysm were based on angio-tomography, employing a 64-channel multi-slice computed tomography scan with $1 \mathrm{~mm}$ slices in all cases. Preoperative arteriography was an optional diagnostic method. All computed tomography scans were reproduced using OSIRIX ${ }^{\circledR}$ software in 3D and multi-planar reconstruction (MPR) modes. Therefore, it was possible to obtain the diameters, angles, and lengths of the proximal aortic neck, aneurysm, and aortoiliac bifurcation (Figure 1).

Anaconda ${ }^{\mathrm{TM}}$ is a tri-modular stent graft consisting of a nitinol dual-ring design and coated with woven Dacron. The proximal part of the graft body consists of two nitinol rings that provide radial strength for passive sealing of the proximal neck. Active fixation is provided by four pairs of hooks (two anterior pairs and two lateral pairs), which are not required for suprarenal or juxta-renal fixation. The stent graft diameter must be $10 \%$ to $20 \%$ greater than the internal diameter of the proximal aortic neck. The main body is connected to a system of nitinol rings, which make it possible for the stent graft to be collapsed and repositioned. The iliac leg consists of a woven Dacron ${ }^{\circledR}$ prosthesis with a series of nitinol rings whose distance varies according to its diameter. The contralateral iliac leg is connected through catheterization and is facilitated by a magnetic guide wire connected to the body of the stent graft. Dilation with a compliant balloon during the operation is only recommended in the case of an initial endoleak, and should not be frequently performed.

All procedures were performed in a haemodynamic monitoring laboratory. Patients were treated under general inhalation anaesthetics. Antimicrobial prophylaxis was administered with $1.5 \mathrm{~g}$ of cefuroxime at the moment of anaesthesia induction. The preferred approach was by the bilateral common femoral artery through open surgical dissection. When this approach was not possible, the external iliac artery was accessed via a retroperitoneal approach.

Radiographic control was performed with the Artis ${ }^{\circledR}$ Flat Panel detector (Siemens, Munich, Germany). When the location of the device was not considered 

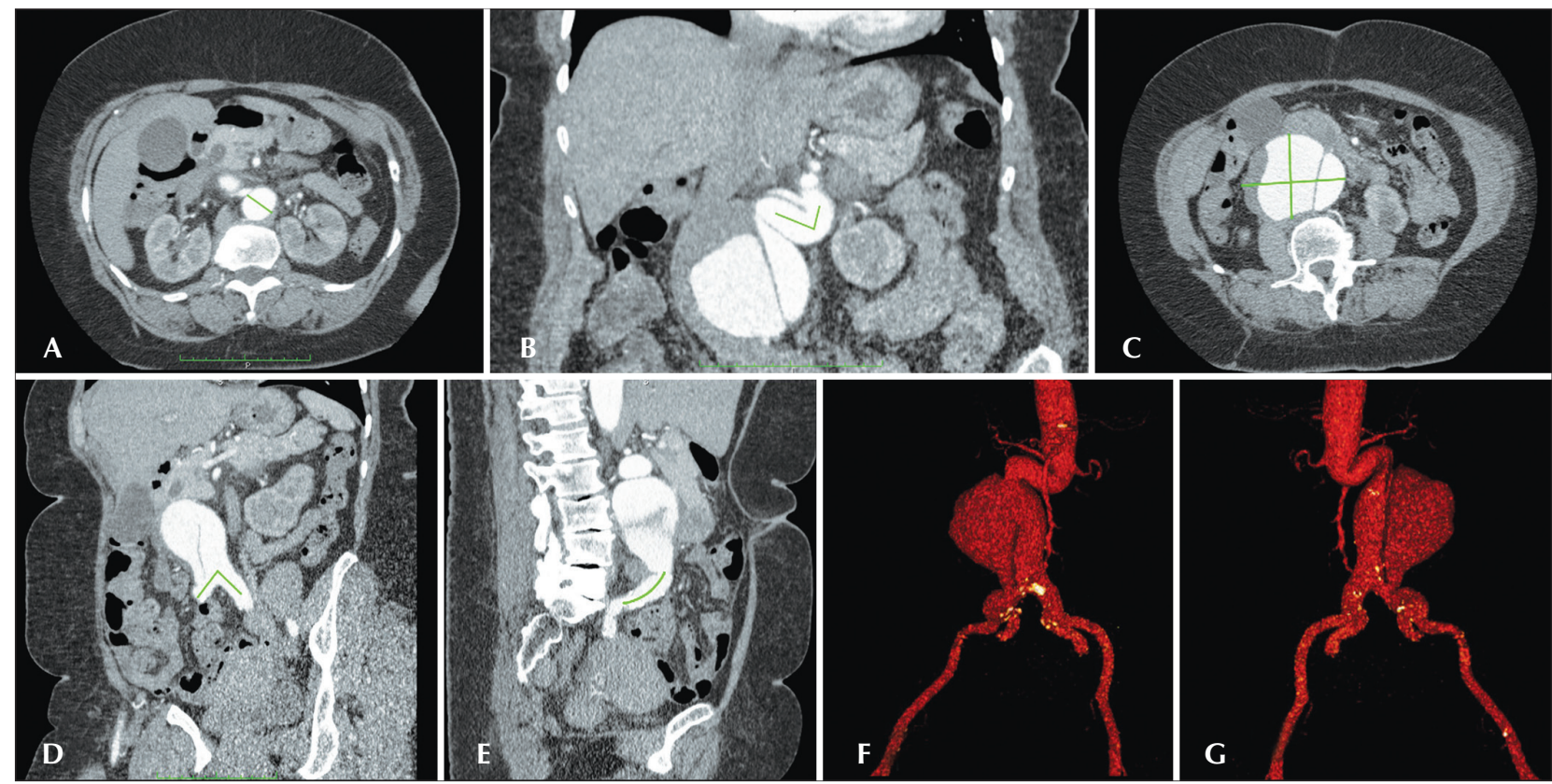

Figure 1 - Angio-tomography showing a three-dimensional multi-planar reconstruction of a complex aortic aneurysm. A shows a 30-mm diameter aortic neck. B shows the neck angle (71 degrees). C shows the greatest diameter of the aneurysm (75 mm). D shows the angle of the aortoiliac bifurcation (82 degrees). E shows the length of the right common iliac artery $(46 \mathrm{~mm})$. F shows a three-dimensional reconstruction (anterior view). $\mathrm{G}$ shows a three-dimensional reconstruction (posterior view).

satisfactory during the positioning of the proximal neck, the device was repositioned in the craniocaudal direction or according to its longitudinal axis. When the first stage was finished, the contralateral iliac leg was introduced after magnetic catheterization of the stent body and then released. When the second stage was finished, the catheterization of the ipsilateral leg was performed, which was finally released and fixed to the stent body. Intraoperative arteriography was performed in all patients (Figure 2). All patients were transferred to the intensive care unit immediately after the procedure.

Outpatient follow-up occurred 15 and 30 days after the procedure. Angio-tomography was performed on the $30^{\text {th }}$ day of outpatient follow-up. Colour-Doppler ultrasound was performed when angio-tomography was contraindicated.

\section{Definitions}

Complex infra-renal abdominal aortic aneurysms present with a proximal aortic neck and/or aortoiliac bifurcation > 60 degrees. Initial or primary endoleaks were defined as those occurring during the initial procedure or those diagnosed within the first 30 days.

Technical success was achieved with the release of the stent graft in the affected area, regardless of the presence of endoleaks or other incidents that could negatively influence the outcome. Therapeutic success was achieved when the release of the stent graft occurred without endoleaks or other incidents that could influence clinical outcomes of the patients.

Peri-procedural complications were classified as intraoperative complications when they occurred during the intervention procedure in the haemodynamic monitoring room, and were classified as perioperative complications when they occurred during the hospital stay, outside the hemodynamic monitoring room, and within 30 days after intervention. The following were considered complications: local bleeding (presence of inguinal or retroperitoneal haematoma); uni- or bilateral occlusion of the renal arteries; presence of peripheral embolization causing acute arterial occlusion; presence of mesenteric ischemia causing vascular acute abdomen; infections (whether surgical site infections or lower respiratory tract infections); acute renal failure ( $>$ two times the increase in the basal creatinine before the procedure); occlusion of the stent graft due to thrombosis; and death.

Reintervention was defined as an intervention performed to maintain the appropriate function of the stent graft and exclude the aneurysm sac, or to resolve complications related to the initial intervention.

In-hospital lenght of stay was defined as the time period between hospital admission and discharge. Procedure time was defined as the period between the beginning of anaesthesia induction and the closure of the operative surgical site. 

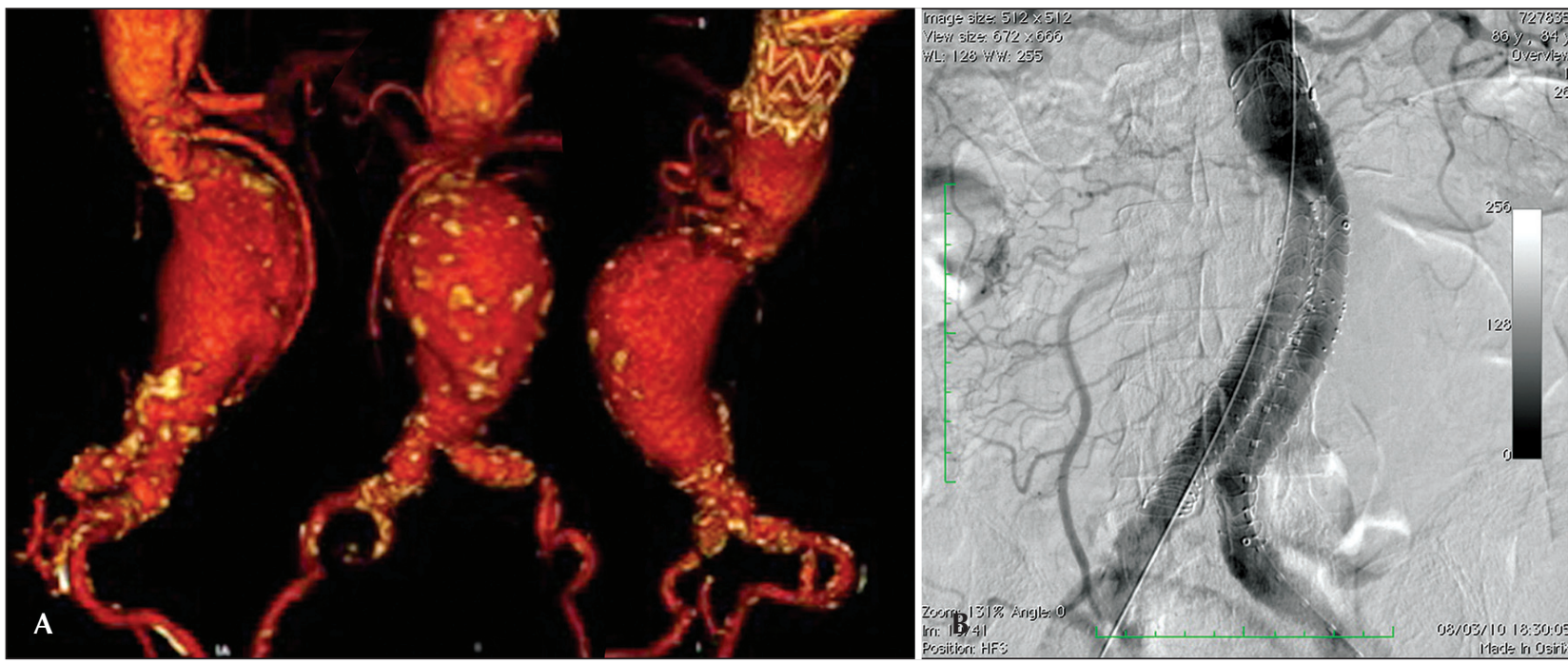

Figure 2 - A shows an angio-tomography of the complex abdominal aortic aneurysm with a proximal aneurysm neck angle $>60$ degrees and aortoiliac bifurcation $>90$ degrees. B shows the endovascular repair with an Anaconda ${ }^{\mathrm{TM}}$ stent graft.

\section{RESULTS}

All patients were asymptomatic, and were electively treated. The average duration of the procedure was 112 minutes (varying from 76 minutes to 155 minutes), and the average in-hospital length of stay period was 4.2 days (minimum: three days; maximum: 14 days).

Sixteen patients who underwent a complex infrarenal abdominal aortic aneurysm repair were analysed. The mean age was $76 \pm 7$ years, and $75 \%$ of the patients were male (Table 1). Among the co-morbidities, the incidence of coronary artery disease was $43.7 \%$, chronic obstructive pulmonary disease was $37.5 \%$, and chronic renal failure was $18.7 \%$. Half of the population were ASA surgery risk $\geq 3$ (according to the criteria of the American Society of Anesthesiology).

In all cases, aneurysm morphology was fusiform. The types of aneurysm treated according to the classification used by the European Collaborators on Stent/graft Techniques for Aortic Aneurysm Repair (EUROSTAR) ${ }^{7}$ (Figure 3) were: type D in four patients (25\%), type $\mathrm{F}$ in six patients $(37.5 \%)$ and type $\mathrm{G}$ in six patients $(37.5 \%)$. Table 2 shows the average diameter of the aneurysm and the characteristics of the proximal neck and the aortoiliac bifurcation.

The tri-modular pattern of the stent graft was used in all cases. It was necessary to use unilateral extensions in five $(31.2 \%)$ of the patients and bilateral extensions in four $(25 \%)$ of the patients. Stent graft repositioning was performed in three cases $(18.6 \%)$.

Technical success was achieved in 94\%; it was possible to release the stent graft at the desired site in 15 patients. In one case it was necessary to convert
TABLE 1

Clinical Data

\begin{tabular}{ll}
\hline Characteristics of the population & $\mathbf{n}=\mathbf{1 6}$ \\
\hline Age, years & $76 \pm 7$ \\
Male gender, $\mathrm{n}(\%)$ & $12(75)$ \\
Asymptomatic disease, $\mathrm{n}(\%)$ & $16(100)$ \\
Severe obesity (BMI > 40 kg/m²), n (\%) & $1(6.2)$ \\
Active tobacco smoking, $\mathrm{n}(\%)$ & $5(31.2)$ \\
Diabetes mellitus, $\mathrm{n}(\%)$ & $4(25)$ \\
Arterial hypertension, $\mathrm{n}(\%)$ & $15(93.7)$ \\
Dyslipidemia, $\mathrm{n}(\%)$ & $12(75)$ \\
\hline BMl = body mass index; $\mathrm{n}=$ number of patients.
\end{tabular}

to an open surgical approach. Therapeutic success was observed in $75 \%$ of the cases; in 12 patients the stent graft was released without an endoleak or other incidents that could negatively influence the outcome.

In three cases (18.7\%), it was necessary to embolize the hypogastric artery during the procedure in order to anchor the iliac leg of the stent graft or its extension in the ipsilateral external iliac artery. There were no cases of pelvic or intestinal ischemia, erectile dysfunction, or buttock claudication at follow-up.

The complication rate was $31.2 \%$, and the most frequent intraoperative complications were operative site bleeding in two cases $(12.5 \%)$, peripheral embolism in two cases $(12.5 \%)$, and occlusion of the bilateral renal arteries in one case $(6.2 \%)$, which required conversion 


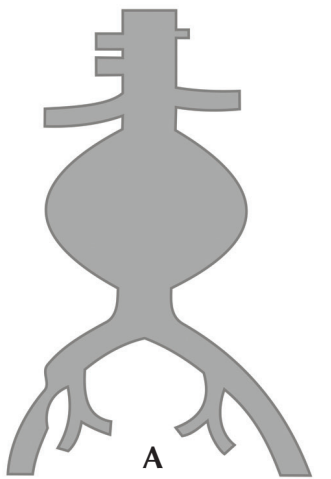

A
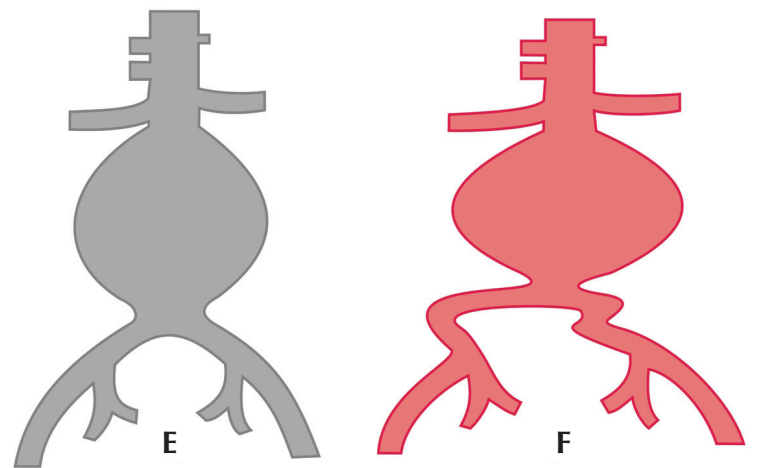

B
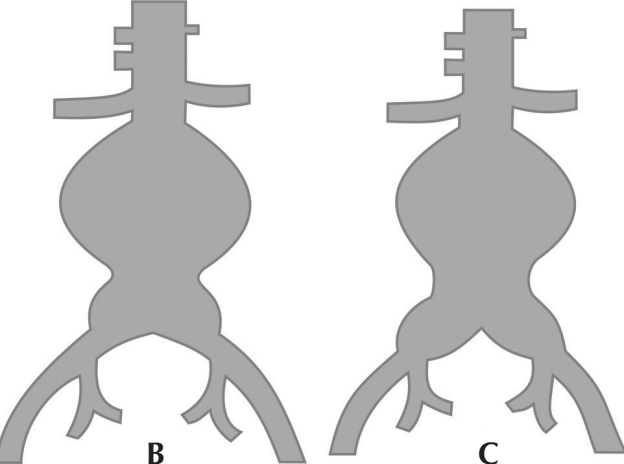

C

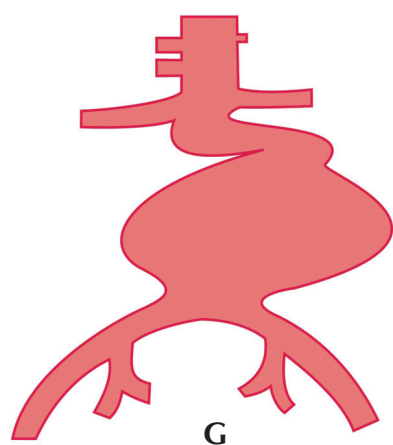

Figure 3 - Classification of abdominal aortic aneurysms - EUROSTAR. (Adapted from Harris et al. ${ }^{7}$ ).

TABLE 2

\section{Angiographic Characteristics}

\begin{tabular}{|c|c|}
\hline \multicolumn{2}{|l|}{ Characteristics } \\
\hline Aneurysm diameter, mm & $71 \pm 16$ \\
\hline \multicolumn{2}{|l|}{ Morphological classification, n (\%) } \\
\hline Type D & $4(25)$ \\
\hline Type F & $6(37.5)$ \\
\hline Type G & $6(37.5)$ \\
\hline $\begin{array}{l}\text { Aortic neck diameter, } \mathrm{mm} \\
\text { (variation) }\end{array}$ & $22(19-30)$ \\
\hline $\begin{array}{l}\text { Aortic neck length, mm } \\
\text { (variation) }\end{array}$ & $19(15-26)$ \\
\hline $\begin{array}{l}\text { Calcification or thrombus in the } \\
\text { aortic neck*, n (\%) }\end{array}$ & $3(18.7)$ \\
\hline $\begin{array}{l}\text { Angle of the proximal aortic neck, } \\
\text { degrees }\end{array}$ & $75 \pm 15$ \\
\hline $\begin{array}{l}\text { Angle of the aortoiliac bifurcation, } \\
\text { degrees }\end{array}$ & $80 \pm 25$ \\
\hline $\begin{array}{l}{ }^{*} \text { Affecting } 25 \% \text { to } 50 \% \text { of the circumfe } \\
n=\text { number of patients. }\end{array}$ & \\
\hline
\end{tabular}

to open surgery. Perioperative infection occurred in one case $(6.2 \%)$. This was an operative site infection that was treated with the use of systemic antibiotics without clinical repercussions for the patient (Table 3). Perioperative mortality was $6.2 \%$. Despite conversion to an open surgery, one patient died because the bilateral renal arteries were occluded due to stent body migration during the operation.

The total endoleak rate was $31.2 \%$, and type I and II endoleaks were present in $25 \%$ (Table 4). The perioperative reintervention rate was $12.5 \%$ due to the treatment of 2 type Ib endoleaks. One patient with a type la endoleak was treated during the operation by insufflating the compliant balloon in the proximal neck, which led to resolution of the endoleak. A type III endoleak, which is caused by inappropriate sealing of the anchoring zone of the iliac legs, was treated in the same way. A type II endoleak, with branches filling the aneurysm sac, was observed in one case on postoperative angio-tomography. Additional interventions due to an increase in the size of the aneurysm sac were not necessary. Two reinterventions to treat a type $\mathrm{lb}$ endoleak and the endoleak of the stent graft iliac leg were necessary; iliac leg extensions were used after surgery. 
TABLE 3

\section{Intra and Perioperative Complications}

\begin{tabular}{lc}
\hline Intraoperative outcomes, $\mathrm{n}(\%)$ & $1(6.2)$ \\
Death & $2(12.5)$ \\
Bleeding & $1(6.2)$ \\
Bilateral renal artery occlusion & $2(12.5)$ \\
Peripheral embolism & \\
Perioperative outcomes, $\mathrm{n}(\%)$ & $1(6.2)$ \\
Infection & $1(6.2)$ \\
Acute renal failure & $1(6.2)$ \\
Occlusion of the stent graft iliac leg & 0 \\
Mesenteric ischemia & \\
\hline $\mathrm{n}=$ number of patients.
\end{tabular}

\section{TABLE 4}

\section{Primary Endoleak Data}

\begin{tabular}{lc}
\hline Type of Endoleak & \\
\hline Total, n (\%) & $5(31.2)$ \\
Type Ia, n (\%) & $1(6.2)$ \\
Type Ib, n (\%) & $2(12.5)$ \\
Type II, n (\%) & $1(6.2)$ \\
Type III, n (\%) & $1(6.2)$ \\
Type IV, n (\%) & 0 \\
\hline $\mathrm{n}=$ number of patients.
\end{tabular}

\section{DISCUSSION}

Endovascular treatment of abdominal aortic aneurysms is a less invasive alternative compared to open surgery, and it is indicated for high-risk patients and for those with appropriate anatomy. ${ }^{8}$ Open surgery is associated with a mortality rate of $2 \%$ to $6 \%$. A mortality rate of $2 \%$ is associated with low-risk cases, but the mortality can be as high as $50 \%$ in cases of ruptured aneurysms. ${ }^{9}$ According to several publications, technological innovations and the experience gained with the use of endovascular techniques over the last 20 years have reduced the mortality rate and have led to results that are similar to or even better than those observed with traditional surgical treatment. ${ }^{4-6,10-13}$

Not all patients can undergo endovascular treatment, and unfavourable anatomy is the main limitation to using this technique. These limitations must be evaluated individually, taking into account the team's experience, the characteristics observed on computed tomography, and the stent graft used. The most important anatomic features that determine endovascular treatment are the tortuosity of the aorta and the diameter, the length of the proximal neck (fixation area for the stent graft), and the access to the iliac-femoral segment. Secondary factors include angulation of the aorta (proximal neck) and iliac arteries, calcification, and the presence of mural thrombus in the proximal neck. ${ }^{14}$

Nowadays, endovascular treatment of abdominal aortic aneurysms with infra-renal fixation devices is recommended for aortas with an anchorage zone $>15 \mathrm{~mm}$, a landing neck diameter < $32 \mathrm{~mm}$, and an aortic neck angulation $<60$ degrees. ${ }^{8}$ Stent grafts with suprarenal fixation have been indicated to provide better sealing to the proximal neck when its morphology is unfavourable due to the short length of the landing neck, severe angulation, extensive calcification, and mural thrombus. Despite the advantages of using stent grafts with suprarenal fixation for complex abdominal aortic aneurysms, it is still necessary to wait for long-term follow-up in order to document the incidence of embolization or renal occlusion. . $^{8,15}$

The Anaconda ${ }^{\mathrm{TM}}$ stent graft is a device that uses infra-renal fixation and consists of a ring design that provides more flexibility and radial strength to adapt to landing necks with unfavourable anatomy. The easy manoeuvring of the delivery system and the hydrophilic coating facilitate navigation through tortuous iliac vessels. The repositionable deployment system enables position correction in the aortic neck. The catheterization system with the contralateral leg facilitates the procedure in patients with pronounced aortoiliac angulations. These features make the stent graft more attractive for the treatment of more complex infra-renal abdominal aortic aneurysms.

In a comparative study using aortic stent grafts in humans aimed at evaluating iliac and aortic fixation, Melas et al. ${ }^{16}$ verified the improved proximal fixation with the Anaconda ${ }^{\mathrm{TM}}$ stent graft versus six other stents from different manufacturers. The improved proximal fixation is due to the presence of four pairs of hooks and the nitinol coating, which provides greater radial strength and an improved proximal seal.

The present study analysed 108 consecutive patients; 16 had complex abdominal aortic aneurysms. Despite anatomic difficulties, technical success was achieved in $94.1 \%$ of the cases. In one patient it was not possible to position and release the stent graft at the appropriate site, and surgical conversion was necessary. In this case, the degree of aortic tortuosity and calcification of the access arteries were underestimated. The literature reports a technical success rate of $94 \%-99 \% .^{13,17}$ In the EUROSTAR registry ${ }^{7}$ it was not possible to advance the delivery system 
of the stent graft in $0.8 \%$ of the cases. Brazilian authors have published a study with 105 patients with abdominal aortic aneurysm undergoing endovascular repair, with a technical success rate of $97.2 \% .^{18}$

In a study published by Perdikides et al. ${ }^{19}$ in 2009, the stent graft with a dual-ring design was used in 20 patients with a complex abdominal aortic aneurysm and the technical success rate was $95 \%$. The mean angulation of the aneurysms of these patients was 62 degrees, the length of the proximal neck ranged from $18 \mathrm{~mm}$ to $30 \mathrm{~mm}$, and the average angulation of the aortoiliac bifurcation was 59 degrees.

The initial technical success rate of the present study was $75 \%$, which was calculated based on the incidence of endoleaks in the primary procedures. In the EUROSTAR registry, ${ }^{7}$ the incidence of an initial endoleak was $4.4 \%$ in type I, $9 \%$ in type $\mathrm{II}$, and $2.4 \%$ in type III. In the population of this study, an initial endoleak was observed in $31.2 \%$ of the cases: $6.2 \%$ were type la (1 case), $12.5 \%$ (2 cases) were type Ib, $6.2 \%$ ( 1 case) were type $\mathrm{II}$, and $6.2 \%$ ( 1 case) were type III endoleaks. Analysing these statistics, four cases (25\%) of type I and III endoleaks were observed. Of these, types la and III were resolved during the procedure by insufflating the balloon in the proximal neck in the case of the type la endoleak and by using the same technique in the iliac leg connection in the case of the type III endoleak. These endoleaks were considered primary endoleaks in this study, since post-dilation with a compliant balloon was not recommended during the initial procedure and was only performed in the case of an endoleak during the aneurysm repair. Angio-tomography performed one month after the procedure confirmed that there was no endoleak in these cases. The remaining two cases of type $\mathrm{lb}$ endoleak were successfully treated with an extension of the iliac leg during the postoperative period, leading to a reintervention rate of $12.5 \%$.

In a study performed by Freyrie et al., ${ }^{3} 49$ patients with abdominal aortic aneurysm were treated with the Anaconda ${ }^{\mathrm{TM}}$ stent graft. They reported a technical success rate of $100 \%$, with no incidence of type I or II endoleak; $25 \%$ had a type II endoleak. In that study, most of the aneurysms had an aortic neck $>20 \mathrm{~mm}$ and a neck angle $<40$ degrees. Other studies using the same stent graft showed a primary endoleak incidence rate of $10 \%$, and a type I and II endoleak rate between $4.8 \%$ and $7.7 \%$. All endoleaks showed favourable aortic anatomy. ${ }^{20}$

In the present study, the mortality rate within 30 days of the procedure was $6.2 \%$. A patient died during conversion to an open surgery due to occlusion of the renal arteries provoked by stent body migration during the procedure. In a Brazilian study, Palma et al. ${ }^{18}$ reported a mortality rate of $5.6 \%$ for patients who had an initial endovascular treatment for an abdominal aortic aneurysm.

The EVAR 1 study ${ }^{4}$ showed a $4.7 \%$ decrease in the perioperative mortality rate for open surgery versus $1.7 \%$ for endovascular treatment, a relative risk reduction of $65 \%$. The EUROSTAR registry ${ }^{7}$ presented a 30-day mortality rate of $1.7 \%$ for minimally invasive treatment, while the DREAM trial ${ }^{13}$ showed a perioperative mortality rate of $4.6 \%$ for open surgery and $1.2 \%$ for endovascular treatment. Brazilian authors showed a less significant decrease in the perioperative mortality rate of $6.5 \%$ and $5.5 \%$ for conventional and endovascular treatment, respectively. ${ }^{21,22}$

According to May and White, ${ }^{23}$ approximately $20 \%$ of the patients treated with an endovascular procedure develop intraoperative complications. Some of them are inversely proportional to the length of the aneurysm neck, that is, the smaller the aneurysm neck, the harder it is to position the endovascular device. At the same time, the greater the number of comorbidities, the greater the risk of intra- and postoperative complications. The DREAM study, ${ }^{13}$ which compared operative mortality and complications after surgical treatment and endovascular treatment, concluded that endovascular treatment is more appropriate due to the lower mortality rate, the type of complications, and due to the significant reduction in systemic complications. The complication rate was $35 \%$ in the EVAR 1 study and $33 \%$ in the EVAR 2 study. 4,6

In this study, the total complication rate was $31.2 \%$ within 30 days after the procedure. Intraoperative bleeding at the surgical site occurred in two cases (two in the inguinal region, in which surgical intervention was not necessary) and peripheral embolization occurred in two cases (one case treated with embolectomy during surgery and the other case, a microembolism, treated with conservative management). These were the most frequent complications. Occlusion of an iliac leg was also observed. This was due to the presence of a calcified plaque close to the iliac extension, which led to thrombosis seven days after the surgery. The occlusion was successfully treated with a crossover femoro-femoral graft.

\section{Limitations of the study}

The limitations of this study were the small sample size and the short follow-up, which limited the conclusions and the possibility of comparing the results with more comprehensive studies.

\section{CONCLUSIONS}

In this study, the second-generation stent graft with a dual-ring design was effective in the treatment of complex infra-renal abdominal aortic aneurysms. Studies 
with a greater number of patients and with mediumand long-term follow-up may define its applicability.

\section{CONFLICTS OF INTEREST}

The authors declare no conflicts of interest.

\section{REFERENCES}

1. Dubost C, Allary M, Oeconomos N. Resection of aneurysm of abdominal aorta: reestablishment of continuity by preserved human arterial graft, with result after five months. AMA Arch Surg. 1952;64(3):405-8.

2. Parodi JC, Palmaz J, Barone HD. Transfemoral intraluminal graft implantation for abdominal aortic aneurysms. Ann Vasc Surg. 1991;5(6):491-9.

3. Freyrie A, Gargiulo M, Rossi C, Losinno F, Testi G, Mauro R, et al. Preliminary results of Anaconda ${ }^{\mathrm{TM}}$ aortic endografts: a single center study. Eur J Endovasc Surg. 2007;34(6):693-8.

4. Greenhalgh RM, Brown LC, Kwong GP, Powell JT, Thompson SG; EVAR trial participants. Comparison of endovascular aneurysm repair with open repair in patients with abdominal aortic aneurysm (EVAR trial 1), 30-day operative mortality results: randomised controlled trial. Lancet. 2004;364(9437):843-8.

5. Stella A, Freyrie A, Gargiulo M, Faggiolo GL. The advantages of Anaconda endograft for AAA. J Cardiovasc Surg (Torino). 2009;50(2):145-52.

6. EVAR trial participants. Endovascular aneurysm repair and outcome in patients unfit for open repair of abdominal aortic aneurysm (EVAR trial 2): randomized controlled trial. Lancet. 2005;365(9478):2187-92.

7. Harris PL, Vallabhaneni SR, Desgranges $\mathrm{P}$, Becquemin JP, van Marrewijk C, Laheij RJ. Incidence and risk factors of late rupture, conversion, and death after endovascular repair of infrarenal aortic aneurysms: the EUROSTAR experience. European Collaborators on Stent/graft techniques for aortic aneurysm repair. J Vasc Surg. 2000;32(4):739-49.

8. Chaikof EL, Brewster DC, Dalman RL, Makaroun MS, Illig KA, Sicard GA, et al. The care of patients with an abdominal aorticaneurysm: the Society for Vascular Surgery practice guidelines. J Vasc Surg. 2009;50(4 Suppl):S2-49.

9. Souza JAM, Alves CMR. Estado da arte no tratamento do aneurisma da aorta abdominal. Rev Bras Cardiol Invasiva. 2005;13(4):287-91.

10. Matsumura JS, Brewster DC, Makaroun MS, Naftel DC. A multicenter controlled clinical trial of open versus endovascular treatment of abdominal aortic aneurysm. J Vasc Surg. 2003;37(2):262-71.
11. Blankensteijn JD, De Jong SE, Prinssen M, van der Ham AC, Buth J, van Sterkenburg SM, et al. Two-year outcome after conventional or endovascular repair of abdominal aortic aneurysms. N Engl J Med. 2005;352(23):2398-405.

12. Saratzis N, Melas N, Saratzis A, Lazarides J, Lazarides J, Ktenidis $\mathrm{K}$, et al. Anaconda aortic stent-graft: single-center experience of a new commercially available device for abdominal aortic aneurysms. J Endovasc Ther. 2008;15(1):33-41.

13. Prinssen M, Verhoeven EL, Buth J, Cuypers PW, van Sambeek MR, Balm R, et al.; Dutch Randomized Endovascular Aneurysm Management (DREAM) Trial Group. A randomised trial comparing conventional and endovascular repair of abdominal aortic aneurysms. N Engl J Med. 2004;351(16):1607-18.

14. Carnevale FC, Nasser F, Oliveira C, Borges MV, Affonso BB Aneurismas de aorta: até onde expandir a indicação do tratamento endovascular? Rev Bras Cardiol Invasiva. 2006;14(1):82-8

15. Cayne NS, Rhee SJ, Veith FJ, Lipsitz EC, Ohki T, Gargiulo NJ, et al. Does transrenal fixation of aortic endografts impair renal function? J Vasc Surg. 2003;38(4):639-44.

16. Melas N, Saratzis A, Saratzis N, Lazaridis J, Psaroulis D, Trygonis $\mathrm{K}$, et al. Aortic and fixation of seven endografts for abdominal-aortic aneurysm repair in an experimental model using human cadaveric aortas. Eur J Vasc Endovasc Surg. 2010;40(4):429-35

17. Carpenter JP, Anderson WN, Brewter DC, Kwolek C, Makaroun M, Martin J, et al.; Lifepath Investigators. Multicenter pivotal trial results of the Lifepath System for endovascular aortic aneurysm repair. J Vasc Surg. 2004;39(1):34-43.

18. Palma JH, Sampaio AM, Miranda F, Rodrigues Alves CM Souza JA, Buffolo E. A change in the treatment of abdominal aortic aneurysms. Arq Bras Cardiol. 2003;81(5):518-25.

19. Perdikides T, Georgiadis DS, Avgerinos ED, Fotis T, Verikokos C, Hopkinson BR, et al. The Aorfix stent-graft to treat infrarenal abdominal aortic aneurysms with angulated necks and/ or tortuous iliac arteries: midterm results. J Endovasc Ther. 2009;16(5):567-76

20. Dalainas I, Moros I, Gerasimidis T, Papadimitriou D, Saratzis N, Gitas CG, et al. Midterm comparison of bifurcated modular endograft versus aorto-uni-iliac endograft in patients with abdominal aortic aneurysm. Ann Vasc Surg. 2007;21(3):339-45

21. Mendonça CT, Moreira RCR, Timi JRR, Miyamotto $M$, Martins $M$, Stanischesk IC, et al. Comparação entre os tratamentos aberto e endovascular dos aneurismas da aorta abdominal em pacientes de alto risco. J Vasc Bras. 2005;4(3):232-42.

22. Mendonça CT, Moreira RCR, Carvalho CA, Moreira BA, Weingãrtner J, Shiomi AY. Tratamento endovascular de aneurismas da aorta abdominal em pacientes de alto risco cirúrgico. J Vasc Bras. 2009;8(1):56-64.

23. May J, White GH. Endovascular treatment of aortic aneurysm. In: Rutherford RB, editor. Vascular surgery. 5th ed. Philadelphia: WB Saunders; 2000. p. 1281-95. 